\title{
Correspondence
}

\author{
Letters to the Editor should not exceed 500 words.
}

Anatomical Knowledge in Medicine. D. A. N. Hoyte, M.D. .................................694

Rhesus Immunization. B. Chown, M.D......694

Patients on Holiday. P. C. Matthew, M.R.C.s. 694 Human Heart Transplantation. W. J. Dempster, F.R.C.S.

Oral Contraceptives and Thromboembolic Disease. M. P. Vessey, M.B., and W. R. S. Doll F.R.C.P., F.R.S...............................696

Cardiac Catheterization in Cardiac Infarction. M. H. Pappworth, M.D................696 Electric Convulsion Therapy. Mary Morison, M.B., and others...............................696

Vaccination against Measles. W. J. Appleyard, B.M. .......................................696

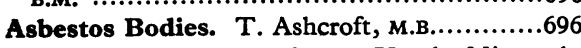

Genetics of Finger-prints. Ursula Mittwoch, PH.D. ..........................................697 Crohn's Disease and Carcinoma of Colon.
R. Wyburn-Mason, M.D.......................697 Guanethidine and Diabetes. K. K. Gupta, M.D. and C. A. Lillicrap, F.R.C.P...................697
Deaths from Asthma. G. R. B. Jones, M.B. 698 Pregnancy and Monoamine Oxidase Inhibitors. Elizabeth Tylden, M.B..................698 Oral Contraceptives in the Post-partum Period. Barbara G. Hinshelwood, M.B., and R. D. Hinshelwood, M.B......................698 Oestrogen Therapy and Migraine. M. A. Chinn, M.D...................................699 Herpes Gestationis and the "Pill." C. P. A. Dupont, L.R.C.P.I., D.P.H. ...................699

Paracervical Block with Bupivacaine. M. J Yates, M.R.C.o.G..............................699 Records System for General Practice. J. K. Hawkey, B.M., and others......................699

General Practitioners and Community Psychiatry. D. C. Pengelly, M.B.................700 Koro in Britain. B. K. Garg, M.D................700

Unusual Complication of Epidural Anaesthesia. T. G. Nash, M.R.C.o.G., and D. J. Openshaw, M.B., D.A.............................700

Factor IX Levels and Oestrogens. D. G. Daniel, M.B., and others. ......................700
Comprehensive Care. D. H. Judson, M.B....701 Peritoneal Lavage in Peritonitis. D. W. Bracey, F.R.C.S.ED.........................701 Duration of Sleep. G. R. A. de M. Rudolf, M.R.C.P. ....................................701 Abdominal Decompression during Pregnancy. J. A. Blecher, F.C.o.G.(s.A.)...........701 Gilbert's Syndrome. I. M. Arias, M.D.........702

Anaesthesia for Insertion of Arteriovenous Cannulae. R. McMillan, M.B................702 Stomal Obstruction after Gastroenterostomy. G. Qvist, F.R.C.S...........................702 Voluntary Sterilization in the Male. L. N. Jackson, D.M.; P. H. Addison, M.R.C.S........702

Heart Transplant Publicity. J. M. Mungavin, M. B. ...............703

Fees for Dental Anaesthetics. E. O. Evans, M.B., D.A..................................703 Prescription Charges. G. E. Spear, M.R.C.P. 703 Religion and Medicine. Dame Annis Gillie, F.R.C.P. ......................................703

\section{Anatomical Knowledge in Medicine}

SIR,-It is perhaps futile nowadays for an anatomist to attempt some defence of some anatomy. Your general practitioner, Dr. David Kyle (27 April, p. 238), perhaps has crossed his pons asinorum too soon. His energies would have been better spent in explaining to his son that, since we cannot make our patients transparent, some knowledge of the course of the circumflex (axillary) nerve in the quadrangular space would render explicable cases of deltoid paralysis following upon dislocation of the shoulder. He should search his or his colleagues' practice experience for cases of brachial plexus injuries and major nerve paralyses to make alive and exciting to his son the applications of anatomical knowledge in everyday medicine. Perhaps it is unnecessary to correlate the palmar bleeding and loss of thumb movement in extensive lacerations of the proximal palm and wrist with injuries to volar arches and a median nerve which have been actually seen and studied at some time by doctors. After all, we can always refer our cases to specialists, relate the sequence of symptoms and signs to the "deep-seated mischief" of our forebears, pass off our patients' inquiries by telling them they have (in other contexts) a "gastric stomach." We can delude ourselves into believing that only reasonably detailed knowledge of more modern disciplines can enable the general practitioner to pick up the early case of syringomyelia or properly advise the sufferer from "painful flat-foot syndrome" or " slipped disc." Are specialists to be the only ones with knowledge and understanding, "ordinary doctors" to learn symptomcomplexes by rote and without understanding ?

One would not wish to enter a blanket defence of traditional anatomy, but to seek in co-operation with colleagues a rational and flexible approach to teaching the fundamentals of structure and function so that medicine does not go back to the days of black magic. This collaboration is not served by the present fashion of abusing anatomy and denigrating anatomists.-I am, etc.,

$$
\text { D. A. N. Hoyte. }
$$

Department of Apatomy, niversity of the West Indies, Kingston, Jamaica.

\section{Rhesus Immunization}

SIR,-For the past two years several university centres in western Canada have been carrying out a co-operative study of the prevention of $R h$ immunization. At a meeting of this group recently I was instructed to bring the following observation to the attention of your readers: something of the order of $3 \%$ of Rh-negative women in the populations we have sampled develop anti-D during their first $\mathrm{ABO}$-compatible $\mathrm{Rh}$-positive pregnancy.

The antibody is demonstrable with certainty by the papain, ficin, or pronase-treated cell technique; in most cases it is not demonstrable by the saline indirect Coombs technique or by an albumin technique. It has a titre of 1 or 2 . The babies are unaffected, and are direct Coombs negative. In most cases the antibody was first demonstrated in a blood specimen taken immediately after delivery. First sign of the antibody has, however been observed at 37 weeks, while in two patients no antibody could be found in the specimen drawn on the day of delivery but was present in one drawn on day 3 . This latter observation is reminiscent of the similar ones reported by Krieger.

In the untreated woman these antibodies may persist in about the same state for six months (we have no later data) or may fade out, becoming imperceptible, or may develop into readily demonstrable indirect Coombs antibodies. Some of the women have been treated within three days of delivery with either $145 \mu \mathrm{g}$. $(0.5 \mathrm{ml}$.) or $435 \mu \mathrm{g}$. $(1.5 \mathrm{ml}$.) of anti-D IgG. ${ }^{2}$ In some of these women an antibody was no longer demonstrable six months later, but the evidence is inadequate to prove that there was a causal relationship between the treatment given and the apparent disappearance of antibody. It seems to us possible that, under as yet undefined conditions, anti-D IgG may abort antibody formation in its early stages.-I am, etc.,

\section{Rh Laboratory, Winnipeg 3} Canada.

Bruce Chown.

\section{REFBRENCES}

Krieger, V. I., f. Obstet. Gynaec. Brit. Cwlth, Connaught Laboratories, Toronto.

\section{Patients on Holiday}

SIR,-Each summer I and my partners have "temporary residents" attending the surgery to get renewal prescriptions for the tranquillizing or antidepressant drugs, and offering a variety of reasons to explain why they have run short-some quite convincing.

We have no personal previous knowledge of these patients, and, having been caught a few times, it is now our practice not to give renewals without firm evidence such as a doctor's letter, or a " copy prescription."

To avoid hardship to the genuine cases, may we ask their doctors to send with them, when possible, a brief note stating what drug they are taking, and in what dose ?-I am, etc.,
St. Ives, Cornwall.
P. C. Matthew. 